\title{
Problemas de Preparação para as OLImpíadas InTERnacionaIS DE Química (II)
}

Co ontinuamos com a publicação da série de problemas reunida pela Sociedade Real de Química do Reino Unido, iniciada no número anterior do Boletim. Séries mais antigas e respostas podem ser encontradas em www.rsc.org/olympiad.

\section{Formas Geométricas em Química}

O fósforo existe sob várias formas alotrópicas, sendo a mais reactiva o fósforo branco. Este foi preparado pela primeira vez no século XVII por redução do fosfato presente na urina.

O fósforo branco sólido contém moléculas de $\mathrm{P}_{4}$, em que cada átomo de $P$ ocupa os átomos os vértices de um tetraedro regular.

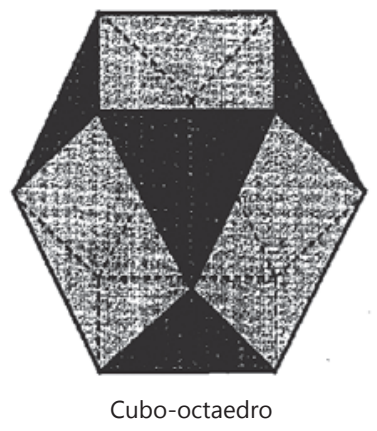

a) Desenha a estrutura de uma molécula de $P_{4}$, mostrando todas as ligações químicas.

b) Quantas arestas há no total num tetraedro regular?

O fósforo branco sofre ignição espontânea se for exposto ao ar para formar uma mistura composta por óxido de fósforo (III) e óxido de fósforo (V).

c) Escreve uma equação para a formação de i) óxido de fósforo (III) e de ii) óxido de fósforo (V) a partir dos elementos.

A estrutura de cada óxido é também baseada num tetraedro regular. Os átomos de fósforo permanecem nos vértices mas deixam de estar directamente ligados uns aos outros, passando a estar ligados por oxigénios em ponte. d) Desenha a estrutura do óxido de fósforo (III).

O óxido de fósforo ( $\mathrm{V}$ ) tem mais um átomo de oxigénio ligado a cada um dos átomos de fósforo que ocupam os vértices do tetraedro.

e) Desenha a estrutura do óxido de fósforo (V).

Cada óxido reage com água para formar um ácido - o óxido de fósforo $(\mathrm{V})$ dá origem ao ácido fosfórico (V), $\mathrm{H}_{3} \mathrm{PO}_{4}$.

f) Desenha a estrutura molecular do ácido fosfórico $(\mathrm{V})$, mostrando todas as ligações.

g) Escreve a reacção de formação do ácido fosfórico $(\mathrm{V})$.

Um método quantitativo para determinar os níveis de fosfato numa solução aquosa involve a adição de molibdato de amónio, $\left(\mathrm{NH}_{4}\right)_{2} \mathrm{MoO}_{4}$, para formar um precipitado de molibdenofosfato de amónio. A estutura deste sólido baseia-se num cubo-octaedro (que se mostra acima). Existe um átomo de molibdénio em cada vértice do cubo-octaedro estando ligados por átomos de oxigénio, com todas as arestas ligadas em ponte por átomos de oxigénio. Um átomo adicional de oxigénio liga-se a cada um dos vértices. No centro da estrutura encontra-se uma única unidade fosfato com os seus quatro átomos de oxigénio coordenando três átomos de molidénio.

h) Calcula o estado de oxidação do molibdénio no molibdato de amónio.

i) Quantos vértices e arestas existem num cubo-octaedro ?

j) Calcula o número de átomos de molibdénio e de oxigénio presentes no ião molibdenofosfato.

k) Considerando que nenhum átomo muda de estado de oxidação durante a formação de molibdenofosfato de amónio, calcula a carga global do ião molibdenofosfato e depois escreve a fórmula do molibdenofosfato de amónio.

\section{AnÁLISE}

Esta questão destina-se a encorajar os alunos a pensarem a três dimensões - especificamente no contexto de poliedros regulares. Não é necessário conhecimento da química das substâncias, embora possa haver alguma vantagem à partida se a química do fósforo tiver sido abordada. $\mathrm{O}$ único conhecimento requerido é o do cálculo dos números de oxidação e da forma de um tetraedro. Os estudantes necessitam interpretar a figura de um cubo-octaedro e as descrições das estruturas dadas na pergunta.

a) Esta molécula tem a forma de um tetraedro em que $P$ se encontra nos vértices, sendo as arestas as ligações simples P-P.

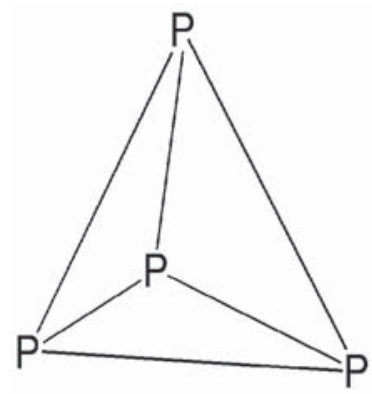

Nota que os ângulos de ligação de $60^{\circ}$ são muito diferentes dos ângulos de ligação óptimos; a tensão de ligações resultante explica a natureza perigosamente reactiva do fósforo branco, $\mathrm{P}_{4}$.

b) As seis arestas de um tetraedro são aqui realçadas dado que são relevantes para a estrutura de óxi- 
dos de fósforo nesta questão. Esta forma particular é interessante dado que é o objecto tridimensional de quatro vértices mais simétrico - os quatro átomos de fósforo nos vértices são simetricamente equivalentes. Com as quatro faces e arestas igualmente equivalentes, o tetraedro é um sólido Platónico. Nota que a soma do número de faces e do número de vértices menos o número de arestas é igual a dois: esta relação é comum a todas as formas tridimensionais.

c) Tendo em consideração o número de oxidação do fósforo em cada um dos óxidos, a fórmula do óxido (+III) é $\mathrm{P}_{2} \mathrm{O}_{3}$ e do óxido $(+\mathrm{V})$ é $\mathrm{P}_{2} \mathrm{O}_{5}$. As duas partes seguintes da questão revelam que $\mathrm{P}_{2} \mathrm{O}_{3}$ e $\mathrm{P}_{2} \mathrm{O}_{5}$ são de facto apenas fórmulas empíricas e que as fórmulas são de facto $\mathrm{P}_{4} \mathrm{O}_{6}$ e $\mathrm{P}_{4} \mathrm{O}_{10}$, respectivamente. É aceitável o uso de fórmulas empíricas ou moleculares para as equações das reacções, i.e.

$\mathrm{P}_{4}+3 \mathrm{O}_{2} \rightarrow 2 \mathrm{P}_{2} \mathrm{O}_{3}$ ou $\mathrm{P}_{4}+3 \mathrm{O}_{2} \rightarrow \mathrm{P}_{4} \mathrm{O}_{6}$ $\mathrm{P}_{4}+5 \mathrm{O}_{2} \rightarrow 2 \mathrm{P}_{2} \mathrm{O}_{5}$ ou $\mathrm{P}_{4}+5 \mathrm{O}_{2} \rightarrow \mathrm{P}_{4} \mathrm{O}_{10}$

d) e e) A informação na questão descreve as estruturas como sendo<smiles>O1p2op3oop(o2)op1o3</smiles>

$\mathrm{P}_{4} \mathrm{O}_{6}$<smiles>O=P12OP3(=O)OP(=O)(O1)OP(=O)(O2)O3</smiles>

$\mathrm{P}_{4} \mathrm{O}_{10}$
A conectividade dos átomos é o aspecto mais importante para o nosso propósito, e não a necessidade de assegurar que a forma global pareça realista. Como estas estruturas são ainda baseadas em quatro átomos de fósforo num arranjo tetraédrico (embora já não directamente ligados uns aos outros), os quatro átomos de fósforo são ainda equivalentes. Os seis oxigénios das "arestas" são também equivalentes. Em $\mathrm{P}_{4} \mathrm{O}_{10}$ as quatro unidades $\mathrm{P}=\mathrm{O}$ são equivalentes. $\mathrm{O}$ número de oxidação indica o número de ligações ao oxigénio para cada fósforo; isto confirma que os quatro átomos de oxigénio extra em $\mathrm{P}_{4} \mathrm{O}_{10}$ estão duplamente ligados aos átomos de fósforo. Uma ligação dativa de $\mathrm{P}$ ao seu oxigénio no vértice satisfaz também as valências dos átomos.

f) A estrutura da molécula do óxido correspondente, $\mathrm{P}_{4} \mathrm{O}_{10}$, que possui uma ligação dupla $\mathrm{P}=\mathrm{O}$ e três ligações simples $\mathrm{P}-\mathrm{O}$, fornece uma pista. Os três hidrogénios em $\mathrm{H}_{3} \mathrm{PO}_{4}$ podem ligar-se aos átomos de oxigénio ligados ao $P$ através de ligação simples para satisfazer a sua valência.<smiles>O=P(O)(O)O</smiles>

Não é necessário especificar a estereoquímica desta estrutura.

g) Como a questão revela as fórmulas do óxido de fósforo ( $\mathrm{V})$ e do ácido fosfórico $(\mathrm{V})$, a equação resume-se à resolução de um balanço

$\mathrm{P}_{4} \mathrm{O}_{10}+6 \mathrm{H}_{2} \mathrm{O} \rightarrow 4 \mathrm{H}_{3} \mathrm{PO}_{4}$

h) Como o ião amónio tem a fórmula $\mathrm{NH}_{4}^{+}$, o ião molibdato deve ser $\mathrm{MoO}_{4}^{2-}$ de modo a garantir o balanço de cargas. A soma dos números de oxidação dos átomos de um ião deve ser igual à sua carga. Ao oxigénio é atribuído o número de oxidação -2 na quase totalidade dos seus compostos (exceptuam-se os peróxidos), pelo que o número de oxidação do molibdénio, N.O. (Mo) determina-se pela relação:

$$
\text { N.O.(Mo) }+(4 x(-2))=-2 \text {, pelo que, }
$$$$
\text { N.O. }(\mathrm{Mo})=+6
$$

i) Como as arestas da parte de trás do cubo-octaedro estão representadas na figura a tracejado é fácil contar o número de arestas e de vértices, obtendo-se 24 arestas e 12 vértices. Podem obter-se esses valores considerando os tipos de faces envolvidas no cubo-octaedro. A figura mostra que há seis faces quadradas que têm vértices comuns mas não têm arestas comuns. Por observação mais atenta conclui-se que cada aresta no cubo-octaedro está associada com um dos qua- drados. Cada quadrado tem quatro arestas, obtendo-se um total de 24 arestas no cubo-octaedro. Uma linha de análise semelhante aplicada às oito faces triangulares mostra que há, no total, 24 arestas. É interessante notar que cada vértice liga duas faces quadradas e duas triangulares; todos os 12 vértices são equivalentes. Cada aresta liga uma face quadrada com uma face triangular; todas as 24 arestas são equivalentes. Com todos os vértices e todas as arestas equivalentes, mas com diferentes tipos de faces, o cubo-octaedro é um sólido Arquimediano.

j) Como há 12 vértices no cubo-octaedro, há 12 átomos de molibdénio no ião molibdenofosfato. Um átomo de oxigénio encontra-se no centro de cada aresta e ainda um ligado a cada vértice (como em $\mathrm{P}_{4} \mathrm{O}_{10}$ ), dando um total de 12+24=36 átomos de oxigénio que fazem parte do cubo-octaedro. Há ainda 4 átomos de oxigénio na unidade fosfato localizada no centro do cubo-octaedro, dando um total global de 40 átomos de oxigénio no molibdenofosfato.

k) Estabelecemos, na alínea anterior, que o ião tem a fórmula $\mathrm{Mo}_{12} \mathrm{PO}_{40}{ }^{\mathrm{n}-}$. A carga é muito provavelmente negativa para compensar a carga positiva dos iões amónio. Podemos determinar a carga do ião adicionando os números de oxidação de todos os átomos $(\mathrm{Mo}=+6, \mathrm{P}=+5$, $\mathrm{O}=-2)$ :

$(12 \times 6)+5+(40 x(-2))=-3$

Assim, a fórmula do molibdenofosfato de amónio é $\left(\mathrm{NH}_{4}\right)_{3} \mathrm{Mo}_{12} \mathrm{PO}_{40}$.

\section{Os Espectros dos Haloalcanos}

Os haloalcanos têm sido usados como popelentes de aerossóis e refrigerantes mas encontram-se actualmente banidos devido ao seu efeito prejudicial sobre a camada de ozono. "Halon 1211 " foi, em tempos, muito usado em extintores de fogos (sendo hoje apenas usados em aviões de combate) e "Halotano" é um anestésico geral de inalação.

A tabela da página seguinte mostra mais exemplos de haloalcanos. 


\begin{tabular}{|l|l|l|}
\hline & \multicolumn{1}{|c|}{ Nome comum } & Fórmula estrutural \\
\hline$A$ & CFC-113 & $\mathrm{Cl}_{2} \mathrm{FC}-\mathrm{CClF}_{2}$ \\
\hline B & CFC-113a & $\mathrm{Cl}_{3} \mathrm{C}-\mathrm{CF}_{3}$ \\
\hline C & HFC-134a & $\mathrm{F}_{3}{\mathrm{C}-\mathrm{CH}_{2} \mathrm{~F}}^{-1}$ \\
\hline D & CFC-11 (Freon-11, R-11) & $\mathrm{CCl}_{3} \mathrm{~F}$ \\
\hline E & CFC-12 (Freon-12, R-12) & $\mathrm{CCl}_{2} \mathrm{~F}_{2}$ \\
\hline $\mathrm{F}$ & CFC-13 & $\mathrm{CClF}_{3}$ \\
\hline$G$ & Halon 1211 & $\mathrm{CBrClF}_{2}$ \\
\hline$H$ & Brometo de metileno (dibromometano) & $\mathrm{CH}_{2} \mathrm{Br}_{2}$ \\
\hline
\end{tabular}

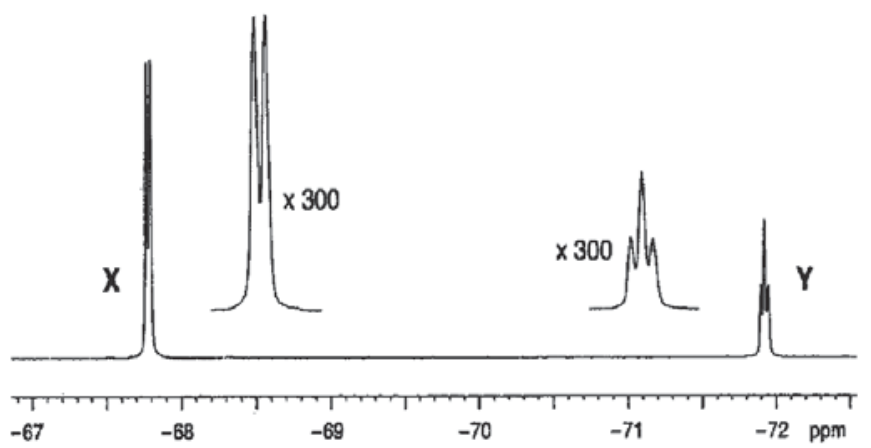

Enquanto que carbono e flúor existem na natureza essencialmente como isótopos únicos ${ }^{12} \mathrm{C} \mathrm{e}{ }^{19} \mathrm{~F}$, o cloro consiste em $75 \%$ de ${ }^{35} \mathrm{Cl}$ e $25 \%$ de ${ }^{37} \mathrm{Cl}$ e o bromo consiste em $50 \%$ de ${ }^{79} \mathrm{Br}$ e $50 \%$ de ${ }^{81} \mathrm{Br}$. A presença de átomos de cloro e de bromo em moléculas conduz, por isso, a padrões característicos para iões moleculares em espectros de massa. Como exemplo, o espectro de massa de CFC-13(F) inclui picos a $\mathrm{m} / \mathrm{z}=104\left(\mathrm{CF}_{3}{ }^{35} \mathrm{Cl}^{++}\right)$e $106\left(\mathrm{CF}_{3}{ }^{37} \mathrm{Cl}^{+}\right)$ com intensidade relativa 3:1.

a) Calcula os valores de $\mathrm{m} / \mathrm{z}$ e as intensidades relativas dos picos dos iões moleculares de CFC-12 (E).

b) Esboça o espectro de massa para os picos dos iões moleculares do Hallon 1211 (G). Indica a intensidade relativa de cada pico e qual o(s) ião(ões) responsáveis por eles.

Uma amostra de brometo de metileno (H) foi enriquecida com deutério $\left({ }^{2} \mathrm{H}\right)$. Por análise descobriu-se que metade do teor de hidrogénio da amostra era constituída por deutério. No espectro de massa há picos de iões moleculares com valores de $\mathrm{m} / \mathrm{z}$ de 172,173 , $174,175,176,177$ e 178.

c) Calcula as intensidades relativas destes picos de iões moleculares.

A espectroscopia de RMN é uma técnica que revela o número de diferentes vizinhanças de certos núcleos numa molécula. Os núcleos activos em RMN, como ${ }^{1} \mathrm{H},{ }^{13} \mathrm{C}$ e ${ }^{19} \mathrm{~F}$, são estudados regularmente. Como exemplo, os dois átomos de hidrogénio no brometo de metileno $(\mathbf{H})$ são equivalentes e, por isso, originam um só pico no espectro de RMN do ${ }^{1} \mathrm{H}$. O mesmo se verifica para os hidrogénios de HFC$-134 a(\mathbf{C})$.

d) Completa a tabela abaixo indicando o número de diferentes vizinhanças dos átomos de flúor para cada um dos compostos A-G.
ANÁLISE

Esta é uma pergunta mais exigente sobre espectrometria de massa e

\begin{tabular}{|l|l|l|l|}
\hline & \multicolumn{1}{|c|}{ Nome comum } & Fórmula estrutural & \multicolumn{1}{|c|}{ Número de diferentes vizinhanças do flúor } \\
\hline A & CFC-113 & $\mathrm{Cl}_{2}{\mathrm{FC}-\mathrm{CClF}_{2}}_{2}$ & \\
\hline B & CFC-113a & $\mathrm{Cl}_{3} \mathrm{C}-\mathrm{CF}_{3}$ & \\
\hline C & HFC-134a & $\mathrm{F}_{3} \mathrm{C}-\mathrm{CH}_{2} \mathrm{~F}$ & \\
\hline D & CFC-11 (Freon-11, R-11) & $\mathrm{CCl}_{3} \mathrm{~F}$ & \\
\hline E & CFC-12 (Freon-12, R-12) & $\mathrm{CCl}_{2} F_{2}$ & \\
\hline F & CFC-13 & $\mathrm{CClF}_{3}$ & \\
\hline G & Halon 1211 & $\mathrm{CBrClF}_{2}$ & \\
\hline
\end{tabular}

e) O anestésico Halotano tem a fórmula $\mathrm{C}_{2} \mathrm{HBrClF}_{3}$ e mostra apenas um sinal no seu espectro de RMN de ${ }^{19} \mathrm{~F}$. Desenha duas possíveis estruturas tridimensionais do Halotano.

A intensidade de um sinal num espectro de ${ }^{1} \mathrm{H}$ ou ${ }^{19} \mathrm{~F}$ é proporcional ao número de núcleos nessa vizinhança particular.

f) Para cada composto com mais do que um sinal no seu espectro de RMN de ${ }^{19} \mathrm{~F}$, indica na coluna adequada da tabela a razão de intensidades esperada.

Os espectros de RMN são complicados pelo acoplamento entre núcleos. Se um núcleo activo em RMN está até três ligações de outro núcleo semeIhante que se encontra numa vizinhança química diferente, o seu sinal será desdobrado em vários picos em vez de aparecer apenas um único pico. Se um núcleo ficar acoplado a $n$ núcleos activos em RMN, o seu sinal desdobra-se num total de $(n+1)$ picos.

g) $\mathrm{O}$ espectro de $\mathrm{RMN}$ de ${ }^{19} \mathrm{~F}$ de um dos haloalcanos da tabela mostra-se a seguir. Desenha a estrutura do haloalcano e indica com uma seta quais os átomos de flúor que originam os sinais $\mathbf{X}$ e $\mathbf{Y}$.
RMN porque os estudantes precisam considerar as razões mássicas num espectro de massa com mais do que um elemento com múltiplos isótopos e o RMN involve os núcleos de ${ }^{19} \mathrm{~F}$ pouco familiares. Contudo, ${ }^{19} \mathrm{~F}$ comporta-se de modo semelhante ao ${ }^{1} \mathrm{H}$ em RMN e, por isso, são aplicáveis os princípios familiares.

a) Com dois átomos de cloro na molécula, cada um com dois isótopos possíveis, o ião molecular pode ser obtido com quatro combinações possíveis, embora dois deles tenham a mesma massa:

$\mathrm{CF}_{2}{ }^{35} \mathrm{Cl}^{35} \mathrm{Cl}^{+}$

Massa $=12+(2 \times 19)+(2 \times 35)=120$

$\mathrm{CF}_{2}{ }^{35} \mathrm{Cl}^{37} \mathrm{Cl}^{+}$

Massa $=12+(2 \times 19)+35+37=122$

$\mathrm{CF}_{2}{ }^{37} \mathrm{Cl}^{35} \mathrm{Cl}^{+}$

Massa $=12+(2 \times 19)+37+35=122$

$\mathrm{CF}_{2}{ }^{37} \mathrm{Cl}^{37} \mathrm{Cl}^{+}$

Massa $=12+(2 \times 19)+(2 \times 37)=124$

A probabilidade de detectar cada uma das espécies é o produto da probabilidade de encontrar cada um dos isótopos, onde $\mathrm{P}\left({ }^{35} \mathrm{Cl}\right)=3 / 4$ e $\mathrm{P}\left({ }^{37} \mathrm{Cl}\right)=1 / 4$.

Portanto, 
$\mathrm{P}\left(\mathrm{CF}_{2}{ }^{35} \mathrm{Cl}^{35} \mathrm{Cl}^{+}\right)=(3 / 4) \times(3 / 4)=9 / 16$

$\mathrm{P}\left(\mathrm{CF}_{2}{ }^{35} \mathrm{Cl}^{37} \mathrm{Cl}^{+}\right)=\mathrm{P}\left(\mathrm{CF}_{2}{ }^{37} \mathrm{Cl}^{35} \mathrm{Cl}^{+}\right)$

$=(3 / 4) \times(1 / 4)=3 / 16$

$\mathrm{P}\left(\mathrm{CF}_{2}{ }^{37} \mathrm{Cl}^{37} \mathrm{Cl}^{+}\right)=(1 / 4) \times(1 / 4)=1 / 16$

A razão de intensidades dos picos a 120, 122 e 124 é a razão das probabilidades calculadas para cada massa, que são convenientemente obtidas acima em fracções de denominador 16. Assim, as razões são 9:6:1 dado que há duas espécies, cada com probabilidade $3 / 16$, contribuindo para 0 pico de 122.

b) Esta alínea é muito semelhante à alínea a) com dois átomos da molécula possuindo, cada um deles, dois isótopos. A diferença é que as duas combinações de isótopos com a mesma massa não têm igual probabilidade:

$\mathrm{CF}_{2}{ }^{35} \mathrm{Cl}^{79} \mathrm{Br}^{+}$Massa $=164$ Probabilidade $=(3 / 4) \times(1 / 2)=3 / 8$

$\mathrm{CF}_{2}{ }^{35} \mathrm{Cl}^{81} \mathrm{Br}^{+}$Massa $=166$ Probabilidade $=(3 / 4) \times(1 / 2)=3 / 8$

$\mathrm{CF}_{2}{ }^{37} \mathrm{Cl}^{79} \mathrm{Br}^{+}$Massa $=166$ Probabilidade $=(1 / 4) \times(1 / 2)=1 / 8$

$\mathrm{CF}_{2}{ }^{37} \mathrm{Cl}^{81} \mathrm{Br}^{+}$Massa $=168$ Probabilidade $=(1 / 4) \times(1 / 2)=1 / 8$

Adicionando as probabilidades para os dois picos de massa 166, a razão das intensidades dos picos a 164, 166 e 168 é pois 3:4:1. O espectro deve assim assemelhar-se a:

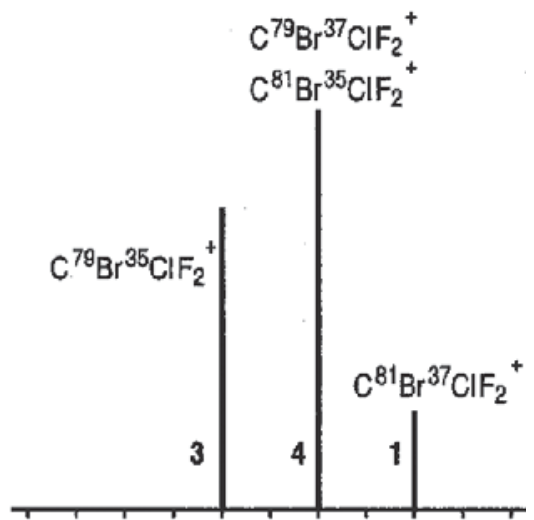

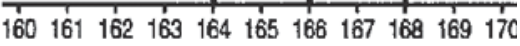

c) $\mathrm{Na}$ amostra de brometo de metileno, após o enriquecimento com deutério, os quatro átomos ligados ao carbono correspondem a dois isótopos numa razão 50:50 - ${ }^{1} \mathrm{H}$ e ${ }^{2} \mathrm{H}$, e ${ }^{79} \mathrm{Br}$ e ${ }^{81} \mathrm{Br}$. Há, portanto, $2 \times 2 \times 2 \times 2=16$ isómeros, embora alguns possuam a mesma massa. $O$ mais leve será $\mathrm{C}^{1} \mathrm{H}^{1} \mathrm{H}^{79} \mathrm{Br}^{79} \mathrm{Br}^{+}$, com

uma massa de 172, e o mais pesado $\mathrm{C}^{2} \mathrm{H}^{2} \mathrm{H}^{81} \mathrm{Br}^{81} \mathrm{Br}^{+}$, com um massa de 178. Ambos estes isómeros têm uma probabilidade de $(1 / 2) \times(1 / 2)$ $x(1 / 2) x(1 / 2)=1 / 16$. De facto, todos os isómeros têm esta probabilidade dado que a probabilidade de um isótopo estar presente é $1 / 2$. Isto significa que esta questão se resume à contagem do número de isómeros de cada valor de massa.

\begin{tabular}{|l|l|l|}
\hline \multicolumn{1}{|c|}{ Massa } & \multicolumn{1}{|c|}{ Isómeros } & \multicolumn{1}{|c|}{ Intensidade relativa } \\
\hline 172 & $\mathrm{C}^{1} \mathrm{H}^{1} \mathrm{H}^{79} \mathrm{Br}^{79} \mathrm{Br}^{+}$ & 1 \\
\hline 173 & $\mathrm{C}^{2} \mathrm{H}^{1} \mathrm{H}^{79} \mathrm{Br}^{79} \mathrm{Br}^{+}, \mathrm{C}^{1} \mathrm{H}^{2} \mathrm{H}^{79} \mathrm{Br}^{79} \mathrm{Br}^{+}$ & 2 \\
\hline 174 & $\mathrm{C}^{2} \mathrm{H}^{2} \mathrm{H}^{79} \mathrm{Br}^{79} \mathrm{Br}^{+}, \mathrm{C}^{1} \mathrm{H}^{1} \mathrm{H}^{81} \mathrm{Br}^{79} \mathrm{Br}^{+}, \mathrm{C}^{1} \mathrm{H}^{1} \mathrm{H}^{79} \mathrm{Br}^{81} \mathrm{Br}^{+}$ & 3 \\
\hline 175 & $\mathrm{C}^{2} \mathrm{H}^{1} \mathrm{H}^{81} \mathrm{Br}^{79} \mathrm{Br}^{+}, \mathrm{C}^{2} \mathrm{H}^{1} \mathrm{H}^{79} \mathrm{Br}^{8} \mathrm{Br}^{+}, \mathrm{C}^{1} \mathrm{H}^{2} \mathrm{H}^{81} \mathrm{Br}^{79} \mathrm{Br}^{+}$, & 4 \\
\hline 176 & $\mathrm{C}^{1} \mathrm{H}^{2} \mathrm{H}^{79} \mathrm{Br}^{81} \mathrm{Br}^{+}$ & 3 \\
\hline 177 & $\mathrm{C}^{1} \mathrm{H}^{1} \mathrm{H}^{81} \mathrm{Br}^{81} \mathrm{Br}^{+}, \mathrm{C}^{2} \mathrm{H}^{2} \mathrm{H}^{79} \mathrm{Br}^{81} \mathrm{Br}^{+}, \mathrm{C}^{2} \mathrm{H}^{2} \mathrm{H}^{81} \mathrm{Br}^{79} \mathrm{Br}^{+}$ & 2 \\
\hline 178 & $\mathrm{C}^{1} \mathrm{H}^{2} \mathrm{H}^{81} \mathrm{Br}^{81} \mathrm{Br}^{+}, \mathrm{C}^{2} \mathrm{H}^{1} \mathrm{H}^{81} \mathrm{Br}^{81} \mathrm{Br}^{+}$ & 1 \\
\hline
\end{tabular}

Consideremos agora os isómeros que diferem de 1 da massa destes extremos. Esta diferença de uma unidade de massa resulta na permuta de um átomo de hidrogénio por um de deutério ou vice-versa. Como há dois átomos de hidrogénio na molécula haverá duas formas de mudar de isótopo, duplicando a probabilidade de encontrar um isómero com essa massa. O isómero com massa 173 é pois $\mathrm{C}^{2} \mathrm{H}^{1} \mathrm{H}^{79} \mathrm{Br}^{79} \mathrm{Br}^{+}$ou $\mathrm{C}^{1} \mathrm{H}^{2} \mathrm{H}^{79} \mathrm{Br}^{79} \mathrm{Br}^{+}$, enquanto que o isómero de massa 177 é $\mathrm{C}^{1} \mathrm{H}^{2} \mathrm{H}^{81} \mathrm{Br}^{81} \mathrm{Br}^{+}$ou $\mathrm{C}^{2} \mathrm{H}^{1} \mathrm{H}^{81} \mathrm{Br}^{81} \mathrm{Br}^{+}$.

Para as massas seguintes afastadas dos extremos - 174 e 176 - há mais possibilidades. Tendo massas que se afastam de duas unidades dos extremos, estas podem obter-se trocando ambos os átomos de hidrogénio por átomos de deutério (ou vice versa) ou trocando um dos isótopos do bromo. Há duas possibilidades de mudar um isótopo de bromo (dado que há dois átomos de bromo na molécula) mas apenas um forma de trocar ambos os isótopos de hidrogénio. Isto dá um total de três isómeros de cada massa, 174 e 176.

Finalmente, há o isómero de massa 175, a qual difere de três unidades da massa dos extremos. Aumentando a massa de três unidades a partir do isómero mais leve pode apenas conseguir-se usando simultaneamente um isómero mais pesado de um hidrogénio e de um bromo (um argumento semelhante pode ser usado para se obter um isómero três unidades mais leve do que o isómero mais pesado).

Contudo, há uma possibilidade de escolha de átomo de bromo e uma de escolha de átomo de hidrogénio, pelo que há quatro isómeros possíveis com pico de massa 175 . Todos estes isómeros estão coligidos na tabela seguinte:
A intensidade relativa é dada pelo número de isómeros possíveis para uma determinada massa, tendo todos os 16 isómeros uma probabilidade de 1/16.

d) Quando há vários átomos de flúor ligados a um átomo de carbono, eles estarão todos na mesma vizinhança. No caso de um grupo $\mathrm{CF}_{3}$, eles serão capazes de rodar para as posições uns dos outros (as ligações simples podem, em regra, rodar livremente) e a rotação é rápida comparada com a escala de tempo do RMN (o espectro é uma média temporal sobre as rotações de ligações); num grupo $\mathrm{CF}_{2}$ os dois átomos de flúor são simetricamente equivalentes dado que há um plano imagem bissectando-os. Portanto, há apenas uma vizinhança para o flúor nos haloalcanos B, D, E, F e G. Em A e C os átomos de flúor estão ligados a diferentes átomos de carbono que não se tornam equivalentes por simetria, pelo que nestes casos há duas vizinhanças para o flúor (ver Tabela na pág.seguinte).

e) Dado que só há um sinal no espectro de RMN de ${ }^{19} \mathrm{~F}$, os três átomos de flúor no halotano devem estar ligados ao mesmo carbono. Por isso, só pode haver um isómero, mas considerando o outro carbono verifica-se que há quatro grupos diferentes ligados a ele $\left(\mathrm{H}, \mathrm{Br}, \mathrm{Cl}, \mathrm{CF}_{3}\right)$, tornando-o um centro quiral. Há, por isso, dois isómeros ópticos que são imagens no espelho um do outro. Eles podem ser distinguidos (ver pág.seg.): 


\begin{tabular}{|c|c|c|c|}
\hline & Nome comum & Fórmula de estrutura & $\begin{array}{l}\text { Número de vizinhanças do } \\
\text { flúor diferentes }\end{array}$ \\
\hline A & CFC-113 & $\mathrm{Cl}_{2} \mathrm{FC}-\mathrm{CClF}_{2}$ & 2 \\
\hline B & CFC-113a & $\mathrm{Cl}_{3} \mathrm{C}-\mathrm{CF}_{3}$ & 1 \\
\hline $\mathrm{C}$ & HFC-143a & $\mathrm{F}_{3} \mathrm{C}-\mathrm{CH}_{2} \mathrm{~F}$ & 2 \\
\hline $\mathrm{D}$ & CFC-1 1 (Freon-1 1, R-1 1) & $\mathrm{CCl}_{3} \mathrm{~F}$ & 1 \\
\hline $\mathrm{E}$ & CFC-12 (Freon-12, R-12) & $\mathrm{CCl}_{2} \mathrm{~F}_{2}$ & 1 \\
\hline $\mathrm{F}$ & CFC-13 & $\mathrm{CClF}_{3}$ & 1 \\
\hline G & Halon 1211 & $\mathrm{CBrClF}_{2}$ & 1 \\
\hline
\end{tabular}<smiles>FC(F)(F)[C@H](Br)I</smiles>

f) Nesta alínea pretende-se identificar o número de átomos de flúor ligados a cada carbono nas moléculas $\mathrm{A}$ e C onde há mais do que uma vizinhança de flúor. A razão é pois 1:2 em $\mathbf{A}$ e 3:1 em $\mathbf{C}$.

g) Há dois sinais de flúor no espectro (X e Y). Portanto, a molécula pode apenas ser $\mathbf{A}$ ou $\mathbf{C}$, dado que apenas estas têm duas vizinhanças para o flúor. Em $A$, dado que não existem átomos de hidrogénio, o desdobramento dos picos só pode dever-se aos outros átomos de flúor (os átomos de carbono e de cloro não são activos em RMN). O sinal do flúor de $\mathrm{Cl}_{2} \mathrm{FC}$ pode esperar-se que seja desdobrado em três picos (i.e. um tripleto) dado que há dois outros átomos de flúor até três ligações de distância numa vizinhança quimicamente diferente. $O$ sinal de flúor de $\mathrm{CIF}_{2} \mathrm{C}$ pode esperar-se que seja desdobrado em dois picos (i.e um dubleto) dado que só há um átomo de flúor a uma distância até três ligações e numa vizinhança quimicamente diferente. $\mathrm{O}$ tripleto e dupleto previstos são as características do espectro em questão, e as intensidades dos picos são também consistentes com uma razão 1:2 dos átomos de flúor nas vizinhanças $Y \mathrm{e}$ $\mathrm{X}$, respectivamente em $\mathbf{A}$.

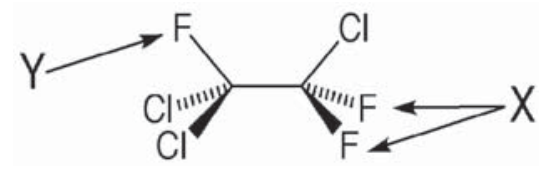

C não é uma resposta possível para esta questão. A presença dos átomos de hidrogénio, que são activos em RMN, complicaria consideravelmente o desdobramento. Mesmo desprezando o efeito dos núcleos de hidrogénio, o espectro de $\mathbf{C}$ exibiria um desdobramento de sinais em quatro picos devido ao acoplamento com $\mathrm{CF}_{3}$.

\section{Os Espectros de RMN dos "NA- noPutianos"}

Em Junho de 2003, foi publicado um artigo científico descrevendo a síntese das formas humanóides mais pequenas: moléculas antropomórficas com $2 \mathrm{~nm}$ de altura, a que os seus criadores deram a alcunha de "NanoPutianos".

As moléculas sintetizadas incluem o "NanoMiúdo", "NanoPasteleiro" e "NanoAtleta". O composto que se mostra abaixo foi designado por "NanoBailarino" e tem a fórmula $\mathrm{C}_{41} \mathrm{H}_{50} \mathrm{O}_{2}$.

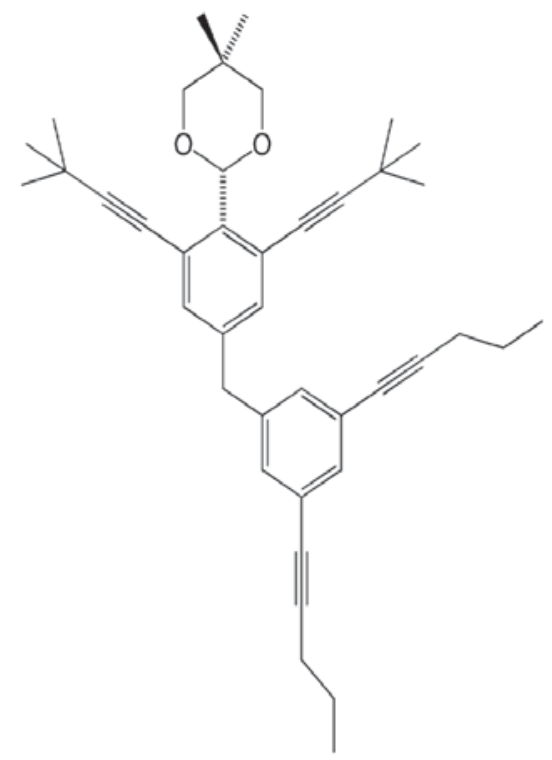

Quando se faz a atribuição de um espectro de RMN, o primeiro passo consiste na identificação de quantos átomos existem em vizinhanças únicas.

Quer os átomos de carbono $\left({ }^{13} \mathrm{C}\right)$ quer os de hidrogénio $\left({ }^{1} \mathrm{H}\right)$ dão origem a sinais de RMN. Cada átomo numa vizinhança diferente origina um sinal. Por exemplo, na estrutura do NanoBailarino, os átomos de carbono $37 \mathrm{e}$ 39 são equivalentes; podemos escrever (37झ39). Assim, embora haja dois átomos de carbono (37 e 39) ligados a um átomo de oxigénio cada, somente se observará um sinal num espectro de RMN de ${ }^{13} \mathrm{C}$ devido a estes átomos, dado que são equivalentes.

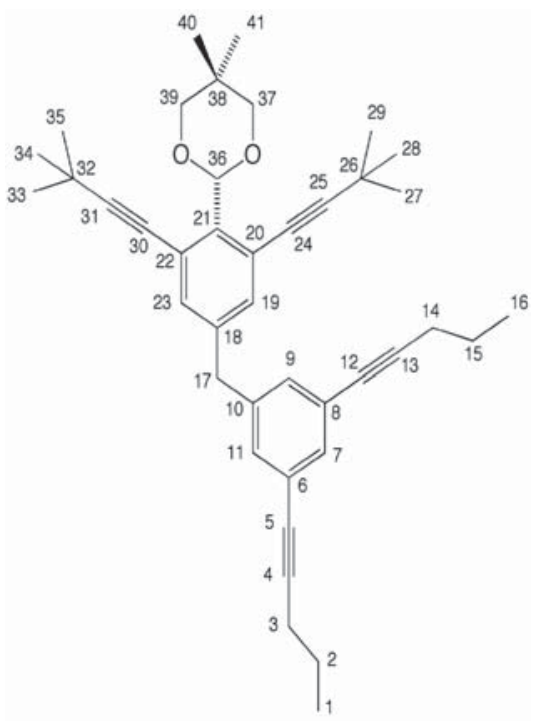

a) Que átomos de carbono que integram os anéis benzénicos são equivalentes ? Escreve $\mathrm{w} \equiv \mathrm{x}, \mathrm{y} \equiv \mathrm{z}$, etc, para quaisquer átomos equivalentes. Quanto sinais, no total, deverão ser observados devido aos átomos de carbono dos anéis benzénicos num espectro de RMN de carbono do NanoBailarino?

b) Lista os grupos de átomos de carbono triplamente ligados equivalentes no NanoBailarino. Quantos sinais seriam detectados no total no espectro de ${ }^{13} \mathrm{C}$ devido aos átomos de carbono ligados triplamente?

c) Quantos grupos metilo (grupos $-\mathrm{CH}_{3}$ ) diferentes existem no NanoBailarino ? Lista-os também em grupos.

d) Quantos átomos de carbono em vizinhanças diferentes existem no NanoBailarino - i.e. quantos sinais deveriam ser observados no total no espectro de RMN de ${ }^{13} \mathrm{C}$ ?

De forma semelhante, no RMN de ${ }^{1} \mathrm{H}$ o número total de sinais depende do número de átomos de hidrogénio em vizinhanças diferentes. No NanoBailarino há 13 vizinhanças diferentes para átomos de hidrogénio; os seus sinais são identificados de A-M no espectro 
abaixo. O número de átomos de hidrogénio em cada vizinhança única é dado sob a legenda. Todos os átomos de hidrogénio em vizinhanças semeIhantes têm desvios químicos semeIhantes. Por exemplo, todos os hidrogénios dos anéis benzénicos ocorrem na mesma região do espectro, i.e. têm semelhante desvio químico.

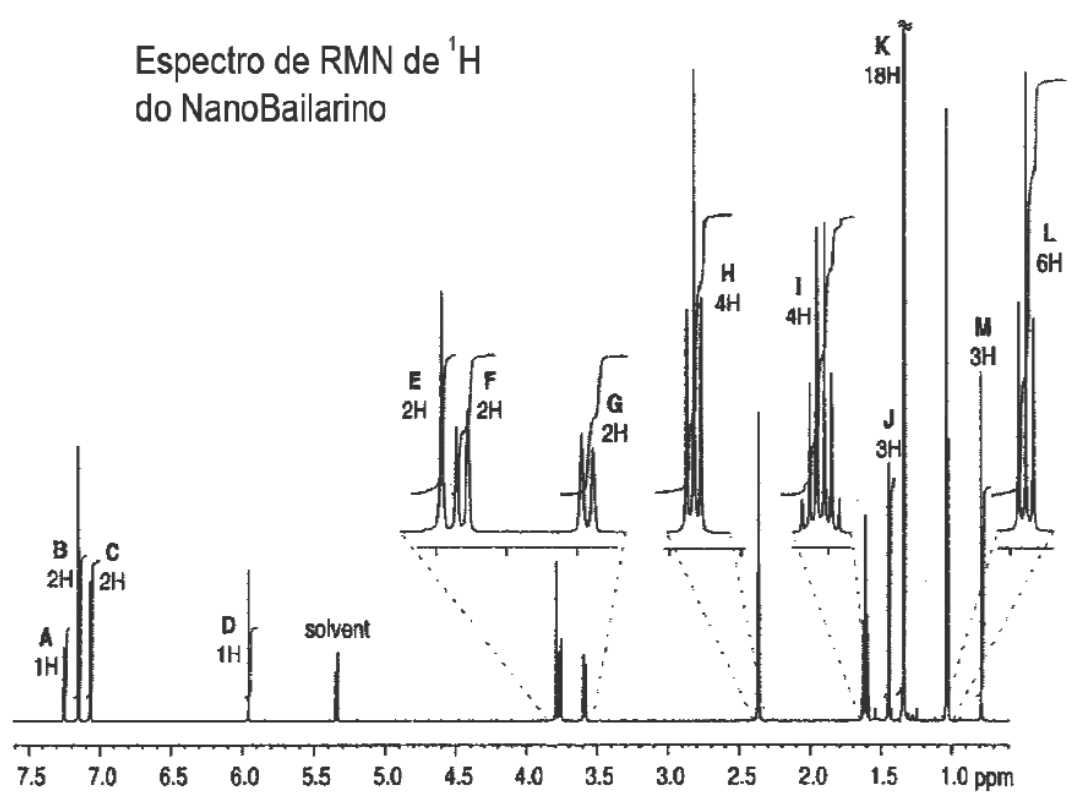

Contudo, o RMN de ${ }^{1} \mathrm{H}$ é complicado pelo acoplamento. Se um hidrogénio se encontrar até três ligações de distância de outro hidrogénio que se encontre numa vizinhança diferente, em vez de um pico, o seu sinal será desdobrado em vários picos. Em geral, se o hidrogénio em análise estiver até três ligações de $n$ hidrogénios numa vizinhança diferente daquela em análise, o seu sinal será desdobrado em $(n+1)$ picos. A razão das áreas sob os picos é dada pelo triângulo de Pascal, como se mostra abaixo.

\section{Razão observada}

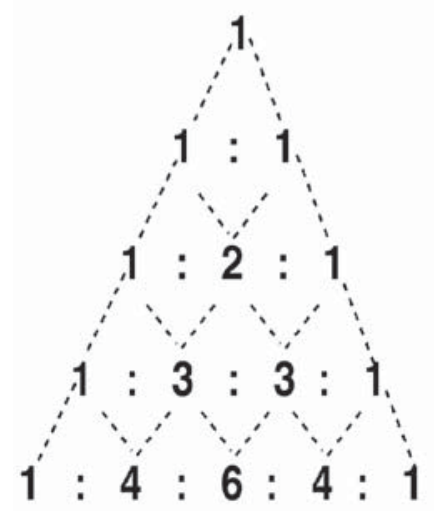

O sinal de um determinado hidrogénio não se desdobra por efeito de outros hidrogénios que se encontrem na mesma vizinhança que ele.

e) Em quantos picos será desdobrado o sinal de um hidrogénio que se acopla a 5 outros hidrogénios ? Qual será a razão dos picos ?

É possível atribuir o espectro de RMN de ${ }^{1} \mathrm{H}$ do NanoBailarino considerando o número de hidrogénios em diferentes vizinhanças, os seus desvios químicos e os seus padrões de acoplamento. Por exemplo, o sinal a 7,15 ppm (B) é devido aos átomos de hidrogénio ligados aos carbonos 19 e 23.

f) Na tabela que se segue, atribui (tanto quanto for possível) os sinais aos átomos de hidrogénio correspondentes. A atribuição para o sinal B já se encontra feita. (Para alguns

\section{para um hidrogénio acoplado a}

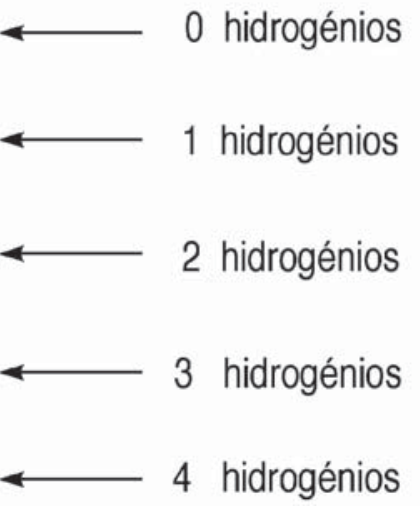

sinais pode não ser possível decidir entre atribuições alternativas - nestes casos escreve “... ou ...").

\begin{tabular}{|l|l|}
\hline $\begin{array}{c}\text { Sinal de RMN } \\
\text { de } H\end{array}$ & $\begin{array}{c}\text { Hidrogénio (s) no(s) } \\
\text { carbono(s) }\end{array}$ \\
\hline A & \\
\hline B & 19,23 \\
\hline C & \\
\hline D & \\
\hline E & \\
\hline F & \\
\hline G & \\
\hline H & \\
\hline I & \\
\hline J & \\
\hline K & \\
\hline L & \\
\hline M & \\
\hline
\end{tabular}

\section{AnÁLISE}

Esta questão foi elaborada para colocar os alunos a pensar na simetria das moléculas. Esta é uma ideia chave na interpretação de espectros de RMN. Dado que todos são familiares com a simetria do corpo humano, as moléculas de "NanoPutian" pareceram a forma ideal de introduzir esta ideia.

A questão inicia-se com RMN de ${ }^{13} \mathrm{C}$ dado que é muito mais fácil de entender do que o RMN de ${ }^{1} \mathrm{H}$. Não existe a complicação dos acoplamentos. Apenas é necessário uma cuidadosa observação da simetria e do número de diferentes vizinhanças dos núcleos de ${ }^{13} \mathrm{C}$.

É fortemente recomendado que se construa um modelo para responder a esta questão. A figura desenhada na pergunta mostra o bailarino a dar um pontapé alto. Pode parecer que a simetria se perdeu.

Contudo, deve recordar-se que pode haver rotação em torno das ligaçõe simples.

Uma rotação em torno da cintura da molécula origina uma estrutura em que a simetria é óbvia. As duas estruturas mostradas abaixo ilustram esta rotação. 

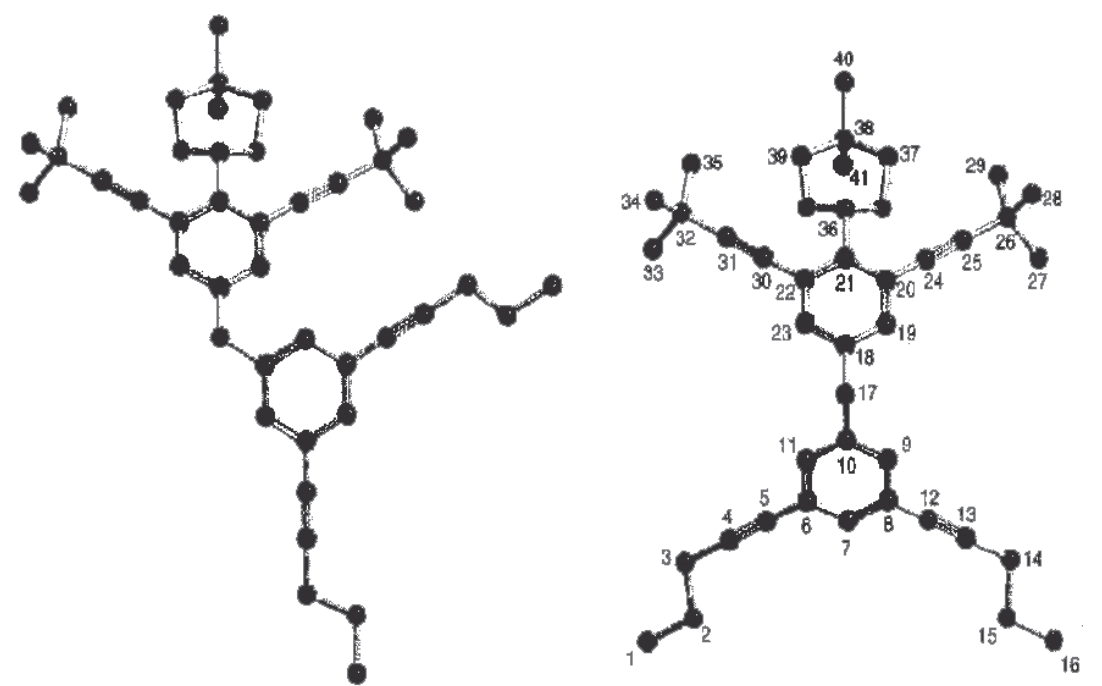

a) Há dois anéis benzénicos na estrutura: um na parte superior do corpo e outro na parte inferior do corpo. Notar que as ligações duplas estão deslocalizadas ao longo do anel pelo que não necessitamos preocupar-nos com a sua posição na estrutura.

Considerando a parte inferior do corpo: O átomo 7 é único, $6 \equiv 8,9 \equiv 11$ e 10 é único. A parte inferior do corpo dá assim origem a quatro sinais no espectro do ${ }^{13} \mathrm{C}$.

\section{Para a parte superior:}

O átomo 18 é único, $19 \equiv 23,20 \equiv 22$ e 21 é único. A parte superior do corpo dá também origem a quatro sinais.

No total haverá oito sinais no espectro de ${ }^{13} \mathrm{C}$ devidos aos carbonos dos anéis benzénicos.

b) As ligações triplas estão nos braços e pernas da estrutura.

Para as pernas: $4 \equiv 13,5 \equiv 12$

Para os braços: $24 \equiv 30,25 \equiv 31$

No total haverá quatro sinais no espectro do ${ }^{13} \mathrm{C}$ devidos aos carbonos com ligações triplas.

c) Os grupos metilo nos pés são equivalentes: $1 \equiv 16$

Todos os grupos metilo dos dedos das mãos são equivalentes: $27 \equiv 28 \equiv 29 \equiv 33 \equiv 34 \equiv 35$

O ponto ligeiramente mais complicado está relacionado com os dois grupos metilo na cabeça, 40 e 41 . Estes são diferentes. Um deles, 41, está no

mesmo lado do anel que faz a cabeça e o corpo (ambos ficam no plano do papel). O outro, 40, está no lado oposto. Embora o anel da cabeça possa rodar, estes grupos metilo nunca serão equivalentes, como se mostra no diagrama abaixo.

este grupo metilo está sempre no mesmo lado do anel da cabeça que o corpo (baixo do plano médio do anel)
Este aspecto pode ser complicado de analisar mas é exactamente o mesmo problema que se coloca quando se conclui que os dois compostos abaixo são diferentes.<smiles>Cl[C@]1CC[C@@](Cl)CC1</smiles><smiles>Cl[C@]1CC[C@](Cl)CC1</smiles>

Estes dois compostos não podem ser interconvertidos sem quebrar ligações.

Podemos assim concluir que há quatro vizinhanças diferentes dos carbo-

nos dos grupos metilo na estrutura: os pés, os dedos das mãos e os dois na cabeça.

d) No total haverá 23 sinais no espectro de RMN de ${ }^{13} \mathrm{C}$ correspondendo aos seguintes grupos:

$\begin{array}{ll}1 & 1 \equiv 16 \\ 2 & 2 \equiv 15 \\ 3 & 3 \equiv 14 \\ 4 & 4 \equiv 13 \\ 5 & 5 \equiv 12 \\ & \\ 6 & 7 \text { (único) } \\ 7 & 6 \equiv 8 \\ & \\ 8 & 9 \equiv 11 \\ 9 & 10 \text { (único) } \\ 10 & 17 \text { (único) } \\ 11 & 18 \text { (único) } \\ 12 & 19 \equiv 23 \\ 13 & 20 \equiv 22 \\ 14 & 21 \text { (único) }\end{array}$

$15 \quad 24 \equiv 30$

$16 \quad 25 \equiv 31$

$17 \quad 26 \equiv 32$

$18 \quad 27 \equiv 28 \equiv 29 \equiv 33 \equiv 34 \equiv 35$

1936 (único)

$20 \quad 37 \equiv 39$

2138 (único)

2240 (único)

2341 (único)

A segunda parte da questão debruça-se sobre o RMN de protão. Esta análise é complicada pelo acoplamento entre protões com diferentes vizinhanças. Contudo, ao tentar atribuir um espectro de $\mathrm{RMN}$ de ${ }^{1} \mathrm{H}$, a primeira coisa a fazer é descobrir quantas vizinhanças diferentes de protões existem de modo a prever quantos sinais separados deverão ser observados no espectro.

No enunciado da pergunta é referido que há 13 vizinhanças diferentes de protões na estrutura, mas vale a pena listá-las, em conjunto com o número de protões que existem em cada vizinhança. Dado que o número de protões contribuindo para cada sinal é dado no espectro, podemos prosse- 
guir atribuindo o espectro sem considerar qualquer acoplamento.

Da discussão na alínea e), concluimos que os quatro hidrogénios que originam

\begin{tabular}{|l|l|l|}
\hline $\begin{array}{c}\text { Número do carbono com } \\
\text { protões }\end{array}$ & \multicolumn{1}{|c|}{$\begin{array}{c}\text { Número de protões } \\
\text { nesta vizinhança }\end{array}$} & \multicolumn{1}{|c|}{$\begin{array}{c}\text { Possível sinal no espectro (apenas } \\
\text { com base no número de protões) }\end{array}$} \\
\hline 1 e 16 & 4 (três em cada) & L \\
\hline 2 e 15 & 4 (dois em cada) & H ou I cada) \\
\hline 3 e 14 & 1 & H ou I \\
\hline 7 & 2 (um em cada) & A ou D \\
\hline 9 e 11 & 2 & B, C, E ou F \\
\hline 17 & 2 (um em cada) & B, C, E ou F \\
\hline 19 e 23 & 18 (três em cada) & B, C, E ou F \\
\hline $27,28,29,33,34,35$ & 1 & L \\
\hline 36 & 2 (um em cada) & A ou D \\
\hline 37 cima e 39 cima & 2 (um em cada) & B, C, E ou F \\
\hline 37 baixo e 39 baixo & 3 & B, C, E ou F \\
\hline 40 & 3 & J ou M \\
\hline 41 & & J ou M \\
\hline
\end{tabular}

Para efectuar as atribuições finais, necessitamos de considerar os padrões de acoplamento.

A informação sobre o acoplamento é dada na pergunta. Estamos apenas interessados nas interacções entre protões que distam até três ligações.

e) Com base no triângulo de Pascal concluimos que um protão que acople com outros cinco protões equivalentes origina o desdobramento de um sinal em seis picos (um sexteto) com razão 1:5:10:10:5:1.

O sexteto é de facto o padrão observado para o sinal I. Os dois hidrogénios equivalentes no carbono 15 são desdobrados pelos 5 hidrogénios até três ligações - três no carbono $16 \mathrm{e}$ dois no carbono 14. Note-se que os hidrogénios no carbono 16 não são os mesmos que no carbono 14 , mas as interacções de acoplamento são suficientemente próximas para que se observe claramente um sexteto no sinal I do RMN.

f) O sinal L resulta dos três hidrogénios no carbono 16 e dos seus equivalentes no carbono 1 . Estes hidrogénios acoplam com os dois hidrogénios na carbono 15 e os dois no carbono 2, respectivamente. $\mathrm{O}$ acoplamento com dois sinais equivalentes desdobra o sinal no tripleto observado no espectro com razão $1: 2: 1$. o sinal I são os dois no carbono 15 e o seu par equivalente no carbono 2.

O outro sinal no espectro que resulta de quatro hidrogénios equivalentes é H. Este é um tripleto claro, o que significa que os hidrogénios equivalentes devem acoplar com apenas outros dois hidrogénios. Os hidrogénios no carbono 14 apenas acoplam com os dois hidrogénios no carbono15, dando assim origem a um tripleto com razão 1:2:1.

Os hidrogénios no carbono 14 são equivalentes ao par no carbono 13, e juntos estes quatro dão origem ao sinal $\mathbf{H}$ no espectro.

Não é fácil decidir entre os singletos $A$ e $\mathbf{D}$ ( devidos a um hidrogénio cada) ou entre os singletos B e C (devidos a dois hidrogénios cada). Os únicos hidrogénios que podiam dar origem a singletos $1 \mathrm{H}$ são os hidrogénios no carbono 36 (o carbono ligados a dois oxigénios) e o hidrogénio no carbono 7 (um carbono aromático).

Os únicos hidrogénios que dão origem a singletos $2 \mathrm{H}$ são os hidrogénios no carbono 17 e aqueles nos carbonos aromáticos 9 (e o correspondente 11) e 19 (e o seu correspondente 23).

Pode esperar-se que todos os sinais devidos a hidrogénios em vizinhanças semelhantes tenham desvios semeIhantes, e assim acontece. Todos os hidrogénios em carbonos aromáticos ocorrem entre 7,0 e 7,3 ppm no espectro. O sinal B já está atribuído como sendo devido aos hidrogénios no anel benzénico do corpo e o sinal A é também devido a um hidrogénio num anel benzénico - carbono 7 . 0 sinal $\mathbf{D}$ é assim devido ao hidrogénio no carbono 36. Os dois hidrogénios no carbono 17 , que não é um carbono aromático, dá origem ao sinal E no espectro.

A distinção entre os sinais $\mathbf{B}$ e C é ainda difícil e isto não é necessário para obter a pontuação total desta questão. De facto, na pergunta, $\mathbf{B}$ já está atribuído. Contudo, para completar a resposta, apresentaremos a forma como se podem distinguir estes sinais. Há uma diferença na aparência destes dois singletos: $\mathbf{B}$ tem quase o dobro da altura de $\mathbf{C}$ embora sejam ambos devidos a dois hidrogénios. A razão pela qual a altura de $\mathbf{C}$ é menor deve-se à existência de uma interacção de acoplamento muito pequena entre os hidrogénios no carbono 9 (e 11) com o hidrogénio no carbono 7 . Estes hidrogénios estão separados por quatro ligações, pelo que a interacção de acoplamento é muito mais fraca do que habitual e não verdadeiramente notada no espectro. Contudo, embora o acoplamento não desdobre o sinal de $\mathbf{C}$ completamente em dois, a interacção implica que o sinal seja mais largo, o que explica a sua menor altura. As áreas sob os sinais B e C são as mesmas mas $\mathbf{B}$ é mais alto e fino, enquanto que o fraco acoplamento significa que $\mathbf{C}$ é mais baixo e largo.

Este mesma interacção de acoplamento fraca também alarga o sinal $\mathbf{A}$ e, de facto, este sinal é mais baixo e largo do que o sinal $\mathbf{D}$, que é mais alto e fino.

Há dois pares de sinais que não somos capazes de atribuir apenas com base no espectro. Estes são os singletos $\mathbf{J}$ e $\mathbf{M}$ e os dupletos $\mathbf{F}$ e $\mathbf{G}$. Os singletos $\mathbf{J}$ e $\mathbf{M}$ são devidos aos grupos metilo ligados à cabeça da molécula. Os hidrogénios destes grupos metilo não estão a três ligações de qualquer outro hidrogénio pelo que não se observa qualquer acoplamento no espectro. Como se discutiu acima, os dois grupos metilo estão em vizi- 
nhanças diferentes pelo que originam dois sinais bem separados.

Os sinais F e $\mathbf{G}$ são talvez mais difíceis de compreender. Estes sinais são devidos aos grupos $-\mathrm{CH}_{2}$ - na parte da cabeça da estrutura. Contudo, os hidrogénios que são equivalentes são os dois hidrogénios que estão para cima (um do lado esquerdo e outro do lado direito) e os dois hidrogénios que estão para baixo (novamente, um no lado esquerdo, e outro no direito).

Estes mostram-se abaixo:
Dentro de cada grupo $-\mathrm{CH}_{2}$ - equivalente, o hidrogénio "para cima" acopla com o hidrogénio "para baixo", dado que são diferentes e separados apenas por duas ligações.

Contudo, não é possível atribuir com precisão qual é qual, apenas com base neste espectro.

A tabela deve então ser completada como se mostra:

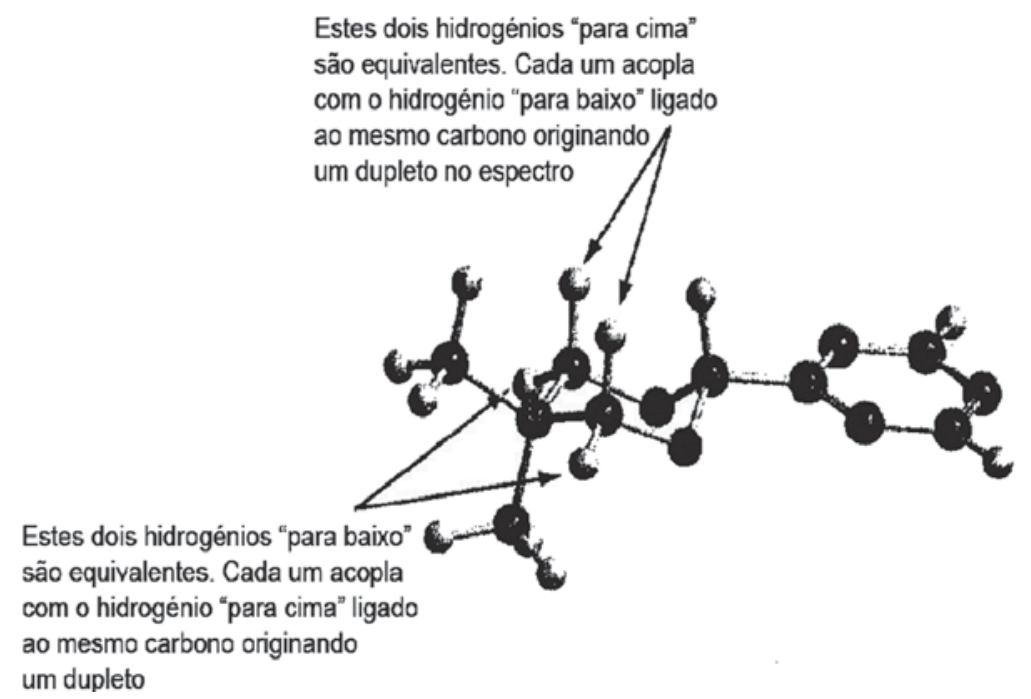

\begin{tabular}{|l|l|}
\hline $\begin{array}{c}\text { Sinal de } \\
\text { RMN de } H\end{array}$ & Hidrogénio(s) no(s) carbono(s) \\
\hline A & 7 \\
\hline B & 19,23 \\
\hline C & 9,11 \\
\hline D & 36 \\
\hline E & 17 \\
\hline F & 37,39 \\
\hline G & 37,39 \\
\hline H & 14,3 \\
\hline I & 15,2 \\
\hline J & 40 ou 41 \\
\hline K & $27,28,29,33,34,35$ \\
\hline L & 16,1 \\
\hline M & 40 ou 41 \\
\hline
\end{tabular}

Jorge Morgado

\section{Actualidade Científica}

\section{USAR A FLUORESCÊNCIA DOS PEIXES PARA DETECTAR MERCÚRIO}

O mercúrio é um poluente altamente tóxico e muito comum. As formas orgânicas do mercúrio (como espécies à base de metilmercúrio, $\mathrm{CH}_{3} \mathrm{HgX}$ (em que $\mathrm{X}=$ halogeneto)) são muito mais tóxicas do que as espécies inorgânicas $\left(\mathrm{HgX}_{2}\right)$.

As formas orgânicas são capazes de atravessar barreiras biológicas, acumulam-se no cérebro, e provocam danos no sistema nervoso central. Afectam também outros órgãos. Por estes motivos têm vindo a ser desenvolvidos sensores de mercúrio, mais comuns para a forma inorgânica. Os sensores de mercúrio inorgânicos usam, sobretudo, ligandos à base de enxofre. Estes são, contudo, pouco sensíveis ao metilmercúrio.
Dois grupos de cientistas sul-coreanos desenvolveram uma nova sonda que reage com ambas as formas de mercúrio. A sonda consiste num éter arilvinílico derivado da fluoresceína, que, nesta forma, é muito pouco fluorescente.

Por reacção com mercúrio ocorre uma hidrólise que origina um álcool fortemente fluorescente, como os autores descrevem em Chemical Communications, 2009, DOI: 10.1039/b900380k.<smiles>C=COc1cc2oc3cc(=O)c(Cl)cc-3c(-c3ccccc3CO)c2cc1Cl</smiles><smiles>C=COc1cc2oc3cc(=O)c(Cl)cc-3c(-c3ccccc3CO)c2cc1Cl</smiles>

Esta reacção é irreversível, pelo que a sonda é essencialmente um doseador químico. A fluorescência verde permite também monitorizar a presença de metilmercúrio em organismos vivos.

Os autores propõem-se agora desenvolverumasondaque permita descriminar o mercúrio inorgânico do orgânico. 


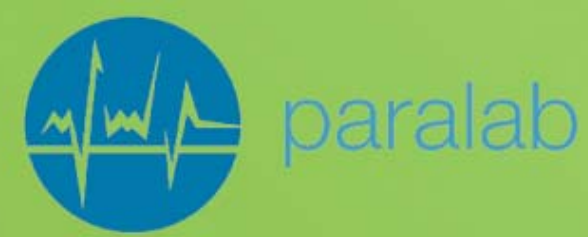

\section{ocean Optics}

\section{Inovação em Espectroscopia}

Incluindo 3 anos de garantia em todos os espectrometros
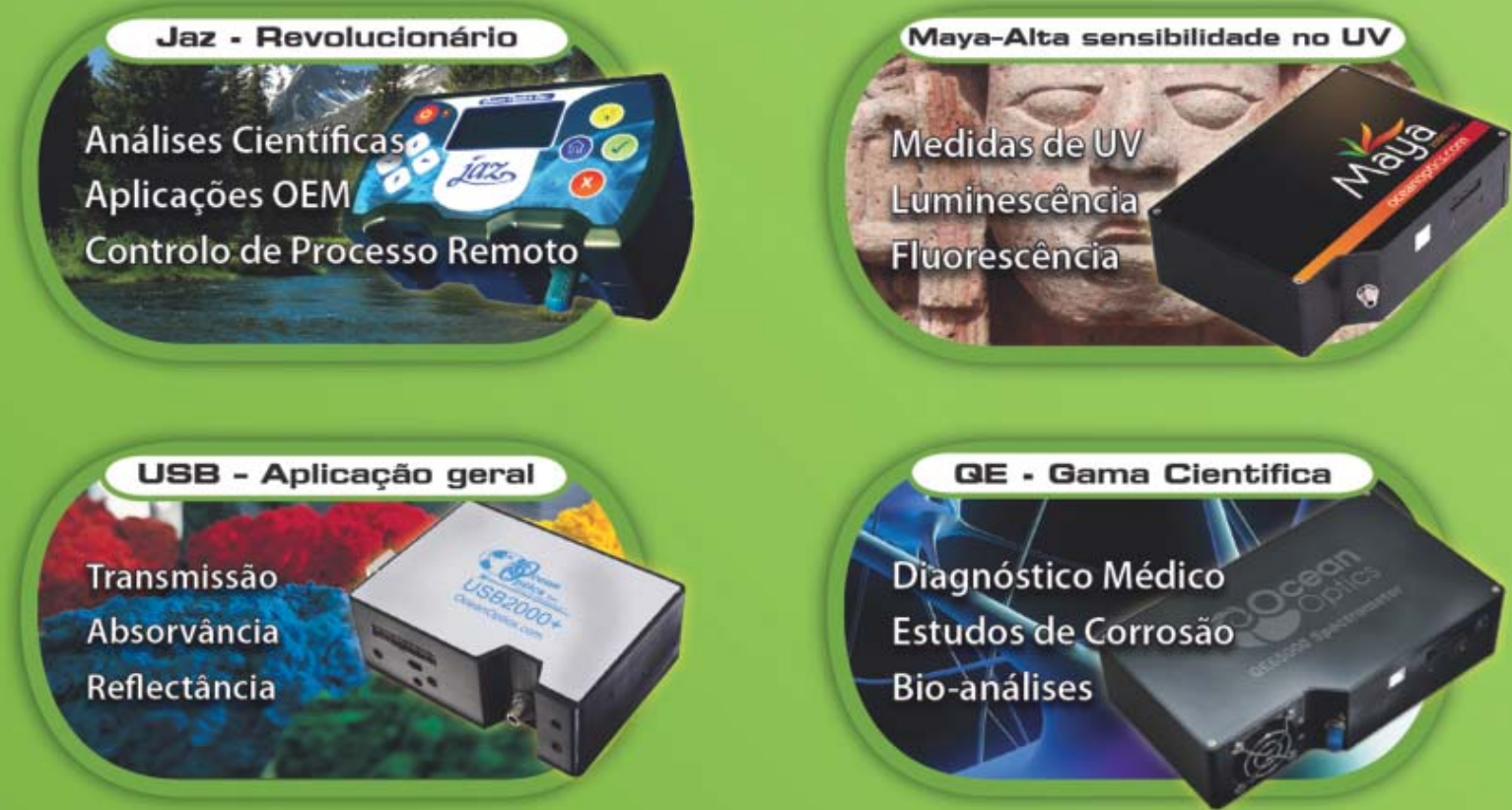

\section{QE - Gama Cientifica}

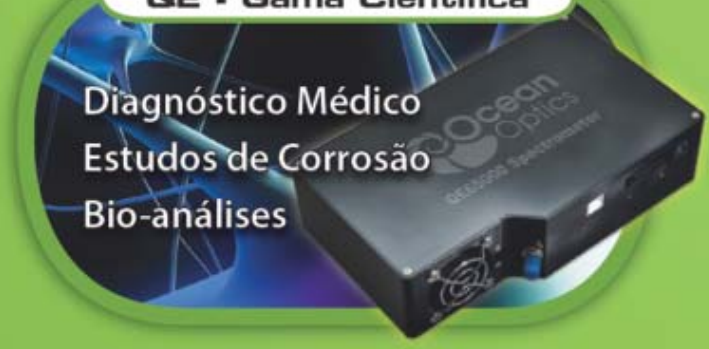

HR - Alta Resolução

Análise de Lasers Análise de Plasmas Irradiância Solar
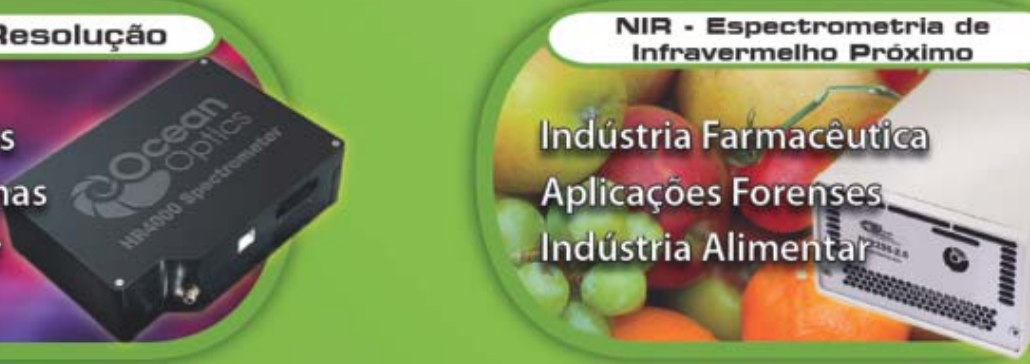

Ligue-nos para o 224664320 para todas suas necessidades de detecção ópticas PARALAB | info@paralab.pt | www.paralab.pt 